\title{
The Recovery of Students' Autonomy for Future Curriculum; Aesthetics of Conflicts
}

\author{
Rina Kim \\ Boston College \\ Email: rina@bc.edu
}

\section{Doi:10.5901/mjss.2014.v5n15p219}

\section{Abstract}

The purpose of this paper is to seek the possible changes in developing curriculum by shedding light upon recent students' efforts to advance it. This process is expected to present the future curriculum and the avenue to education and social evolution. In order to achieve the goal, I drew on System Theory and Yin-Yang Dialectic as the frameworks for this paper; these theories may provide some clues to understand the symbiosis relationship between the curriculum and the students. With new attempts to analyze the relationship based on System Theory and Yin-Yang Dialectics, I looked into conflict between the curriculum and the students along with real cases and how they overcome these conflicts. I also sought the methods for students to recover their autonomy by overcoming conflicts in positive ways. Consequently, I suggested that we needed to listen students' voices and to recognize them as main agents of education in order to lead positive development of the curriculum.

Keywords: curriculum; system theory; Yin-Yang dialectics; symbiosis relationship; South Korea; education;

\section{Introduction}

For whom the curriculum exist. The reason for the presence of the curriculum may support students to develop their own talents (e.g. McNeil, 2009; Bevis \& Watson, 1989; Stainback \& Stainback, 1996), and furthermore lead the changes of the society (e.g. Dewey, 1952). However, the national curriculum or state curriculum that advocate elitism has used the curriculum as a mean of oppressing education agents such as students for satisfying their desires (e.g. Levin, 2008; Westbury, 2008). Indeed, does the curriculum exist for students? Subsequently, is it possible for students to change the curriculum? Is it possible for students to take part in developing a curriculum by applying it with their respective specialties, and taking cooperation?

The purpose of this paper is to seek the possible changes in developing curriculum by shedding light upon recent students' efforts to advance it. This process is expected to present the future curriculum and the avenue to education and social evolution. In order to achieve the goal, this paper draw on System Theory and Yin-Yang Dialectics; these theories may provide some clues to understand the symbiosis relationship between the curriculum and the students. With new attempts to analyze the relationship based on System Theory and Yin-Yang Dialectics, there is a need to look into conflict between the curriculum and the students along with real cases and how they overcome these conflicts. This paper will also seek the methods for students to recover their autonomy by overcoming conflicts in positive ways.

\section{Philosophical Rationale of Symbiosis}

Where does the theoretical rational of symbiosis between curriculum and students? This section is to analyze the feature of the relationship between curriculum and students on System Theory and go through interactions on Yin-Yang Dialectics.

\subsection{System Theory}

In social science, the society is regarded as one system (von Bertalanffy, 1969; Park, 1939). In general, a system indicates a whole composed of various parts of elements. The ecosystem, the organisms including the human body, and even machinery might be defined as systems. In a system, a whole and parts as well as respective parts are interrelated and interdependent with each other. Thus, a change in the whole makes each part changes, and a problem in one part may be metastasized to another part or even the whole. A system with a complex structure is composed of parts of various functions. The human body is a typical example. A human body is made up of organs of various functions, which 
are closely interdependent with each other in working. In case a disease occurs, or a problem arises in an organ, another organ or the whole body will come up against.

The education system is also composed of various parts such as teachers, students, parents, decision makers, and stakeholder who strengthen the interrelation between education and society. In this system, respective parties are closely interrelated and interdependent with each other. The relationship between the curriculum and students is not represented as a dominant-subordinate association, rather they have equal positions to each other, and they are interweaved in diverse ways with mediums such as parents and teachers. Therefore, students are merely not object of the curriculum; students are one of the major components of consisting whole education system such as the curriculum. This shows that if students are not salubrious in the relationship with the curriculum, the curriculum also cannot be vigorous, and this relationship may affect the whole education system.

Accordingly, it needs to understand the functions of students who are interdependent with the curriculum in a system quo parts. Being aware that students have an inseparable relation is a starting point for cooperation, and by extension, for symbiosis. All the interested parties are parts of a system including students, and thus a problem in a part causes to another trouble. At the same time, one flourishes, another undergoes a change under the interdependence. Therein lies the theoretical base for inter symbiosis.

However, in this theory, the description of such symbiosis relationship has not been fully explained yet because the relationship is simplified that has always-positive correlation with each other. Sometimes, good intentions of the curriculum such as national high-stake test cause negative impacts on students (e.g. Roderick, 2005). Therefore, it requires that the interrelation should be reviewed on Yin-Yang Dialectics.

\subsection{Yin-Yang Dialectics}

Yin-Yang Dialectics is based on the Bipolarity theory. It is the most common philosophical idea in Chinese and had wielded the greatest influence upon the Sino sphere. Yin-Yang Dialectics can be summarized as follows; it is grounded on the cosmology that all things in the universe and divided into two such as two types of energy, Yin-Yang. The two, Yin and Yang are in the relativity. Without the existence of one, the other cannot be existent, wherefore the two have to be coexistent. Yin and Yang need each other; Yin is in Yang, and vise versa. Added to that, each of them many change dynamically as to the opposite. This relative relationship between the two is defined by symbiosis or ambivalence. Specifically, the two are different, contradictory and opposite in regard to attribute, but at the same time are complementary, reciprocal and harmonious. In this regards, it is fundamentally inconsistent with Shao-Yang Dialectics that esteems the two are only a contradictory relation. Yin-Yang interacts with each other rotationally and dialectically. Yi and Yang were originated from Taiji, the Great Ultimate. A Confucian scholar in Song Dynasty, Zhou Dun-Yi a described interaction between Yin-Yang as follows.

The activity of Taiji brings Yang into being. The extreme activity is linked to tranquility; the tranquility breeds Yin. The extreme tranquility gets back to the activity. An activity and tranquility have a root from each other. The two respond to each other and interact with each other, thereby producing all things in the universe and changing them. All creation, made like so, develop continuously and change endlessly (Zhou Dun-Yi, 1175).

Subsequently, Yin-Yang Dialectics dichotomize the world, such as day and night, sky and ground, sun and moon, body and mind, reason and intuition, consciousness and unconsciousness, man and woman, which are defined as the vicissitudinous relations between the two cosmic energies. However, these two energies, Yin and Yang, are considered to be equal to each other in importance and to be complementary to each other. They function as beneficial force when being harmonious with each other, but on the other hand, they give out their vicious forces. The vicious force is expressed in the form of conflicts; to be specific, conflicts to remake harmony with each other, not negative conflicts to destroy each other. Therefore, the goal of human life is not to inhibit or remove one of them but to derive the best from them.

In the Figure 1, the thought is schematized. As shown in the figure, the circle has a half that is white and the other one that is dark. They are defined as Yang and Yin respectively. The arrow shows a clockwise movement. As the white part goes up, it becomes bigger; that is, Yin decays but Yang flourishes. The right arrow means that Yang decays but Yin flourishes. 


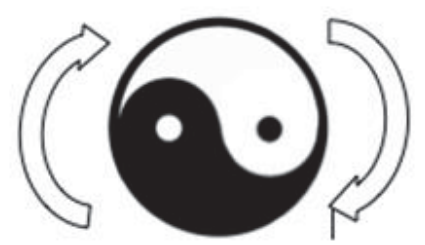

Figure 1. Relationship between Yin and Yang

On System Theory, Taiji embodied in a circle is a closed system, whereof function is influenced by the interaction between Yang and Yin. When Yang flourishes, Yin naturally decays, but the continuous decay of Yin constricts Yang, and as a result Yin flourishes again.

Such a limitation and repetition can be found in the theory of culture change advocated by Sorokin. Sorokin (1957) divided culture into an ideational type and a sensate type, and maintained that if cultural development leans toward one of the two types, it would reach its limit and would decline in the end, wherein the other type would fill. He named a case where the two types are being well-balanced "idealistic type (1957, p.52)." The foregoing shows that Sorokin emphasized the balance, not polarization. Likewise, the equilibrium is particularly prominent in the above-mentioned system. A change in a system is caused by the disequilibrium of parts. A lean or off-balance development breaks the balance, whereby a change occurs.

The relationship between the curriculum and the students might be understood based on the Yin-Yang Dialectics. If the curriculum is robust for better or worse, students' autonomy will be deteriorate. Otherwise, if the curriculum weakens, students' autonomy will be sturdy whether it is worthy or not. Regardless of the value, if the balance of power between the curriculum and students is collapsed, conflicts might occur to recover their harmony again. Subsequently what are aspects of conflicts to recuperate harmony? In the following section, I will provide real cases of conflicts and some clues for how we can overcome these conflicts.

\section{Conflicts for Harmony}

This section is focused on the actual cases of conflicts between the curriculum and education agents, and where such conflicts have been resolved. In this chapter, I will focus on the relationship between the curriculum and students in South Korea, how they overcome the conflicts, and what the implications of it are. The reason why this study is focused on the Korean education system is that the governments, which manage the curriculum, and students who are the beneficiaries of the curriculum are clearly distinguished from each other as regards the role. Therefore, Yin and Yang in their interrelations might be explained more clearly in the cases of South Korean education system.

\subsection{Yin for students, Yang for curriculum}

In South Korea, the Government is directly related to the development and operation of the curriculum, and every student studies according to the curriculum. The South Korean educational authorities, advocating elitism, have intervened excessively in the curriculum and have infringed upon students' autonomy and thus have disturbed the harmony between the education system and student and amongst students. The following shows the drawback of the Korean education system that emphasizes the selective curriculum rather than students' voluntary participation in education.

- The national curriculum is highly controlled by the government in South Korea. The Ministry of Education enacted strict laws about content and objectives of curriculum and let teachers to teach based on the national curriculum (Lee, 1999). The Ministry of Education is in charge of the whole range of school education, including textbooks, teachers, and school management. By taking advantage on this system, the government distorted the truth or chose educational content selectively according to national ideology (Kim, 1996). The Ministry of Education did not introduce most pro-democracy movement or describe them as riots in the textbook during the military regimes of the 1970s and the 1980s in South Korea (Lee, 1997). The government's views on education in terms of control are paralleled to the colonial education system that was dominated by decisions of government.

- The basic premise of the national curriculum in South Korea was to select people who could contribute to the development of society and this caused excessive competition among students (Lee, 2011). The educational 
policy that urged students to be overly competitive had been taken for granted, because of reconstruction of the nation after the Korean War. The South Korean Government enforced the middle school entrance examination until 1969 and provided middle school education to students who were only passed this exam (Ha, 2009). Until the 1990s, middle school students who had low grade-point averages were forced to go to vocational education high schools (Lim, 1997). There still remain high schools that require the entrance examination, which encourages elitism in South Korea, giving rise to a strong sense of rivalry among students.

So far, the South Korean government has taken the lead at the development, operation and application of curriculums; in other words, the Korean education system has been led by the national curriculum. The South Korean educational authorities have pursued the elite-centered education system, and as a result many South Korean students have ranked highly in international tests and more than $90 \%$ of them have gone on to university. There is no question that such performances have been the foundation for hyper growth that Korean society has achieved for the past 50 years. However, the problem is that the elite education system has driven students to limitless competition. Upon entering school, students should get in on excessive competition and are ranked by school credits.

Within this framework of the curriculum, the force of Yang has flourished in the Korean education, but from the viewpoint of students who have led the curriculum, Yang has decayed but Yin has flourished inasmuch as the curriculum has overemphasized and thus has lost ground. Since Yang and Yin has been off-balance, they have come into conflict over the balance; that is, new movements have come up. These movements are shown up as diverse forms of conflicts; sometimes they are negative, but the other times they are positive.

\subsection{Negative Conflicts for Harmony}

Under the excessive competition based on the nation curriculum in South Korea, the students' autonomy is oppressed. Sometimes it explodes as destroying the relationship. It might provide a catalyst for change; however, it is a just revolution without glory. I would refer it as a negative conflict that indicates destructive dissension between two subjects. Although these conflicts might lead changes that balance between two subjects, the process toward harmony is unprofitable to anyone.

The negative conflict between the curriculum and students may be interpreted as abandonment and distrust. Another conflict is bred by students' giving up their studies due to stress brought on by schoolwork or going to extremes to solve the problem. The cases of negative conflicts that hinder mutual improvement are as follows.

- Korea Educational Development Institute announced that 76,489 students, inclusive of elementary schoolchildren, middle and high school students, dropped out of school in 2011. In the case of high school students, dropouts have continuously increased in number since 2008, as of 2011, the number reached 38,787 .

- 'My grades do not go up. Schoolwork is a hard work for me, and moreover English is too difficult for me.' Leaving this note, a middle school student ended his own life. Also, an undergraduate leaped his death, leaving a note: 'I cannot help but shed tears. All passions are extinguished. I've lost interest in everything, and it is no longer being peppy to do something.' In recent times the news has reported students' suicides. In the foregoing two cases, in particular, stress brought on by schoolwork is cited as the cause. National Youth Policy Institute (2011) surveyed the mental health status of 9,400 students last year, and reported that one out of five students contemplated suicide; specifically, $13.7 \%$ of schoolchildren, $23.5 \%$ of middle school students and $21.1 \%$ of high school students. Schoolwork-related stress comprised the highest percentage of the causes.

\subsection{Positive Conflicts for Harmony}

Thenceforth, are students listless in the education system? The answer is 'No.' In recent times they have been showing their power and autonomy. Korean students' recent movements have well showed their power and autonomy.

- Choi dropped out of school in February 2012 and began to hold a one-man demonstration in front of a government building. In his picket, 'Make School Hopeful!' is being written. In an interview on a daily, he said that students are classified into winners and losers with their school credits, which destroys their humanity. $\mathrm{He}$ recognized the necessity of scholastic achievement test and competition, but hoped to reject conformity and value diversity. Now he plans to found a high school together with a group of like-minded persons. He dreams of making a school, in which students can study subjectively without pressure (Lee, 1998). 
- In 2011, Kim dropped out of Seoul National University that is regarded one of the best universities in Korea, and then declared that he would deny the university education. He criticized the elite-centered education system, and contended that education is not in return for efforts or talents but is the right to be granted to students. He maintained that educational opportunities should be equalized, and the present system is not suitable to evaluate students' potentials. He plans on carrying on a campaign for educational changes (Kim \& Lee, 2011).

- On May 31, 1995 Korean President, Kim Young-Sam, announced that globalization should be based on autonomy and competition, the same as businesses or universities, under the slogan of "Choice and Concentration." In result, universities have been classified into grade and many students have leaned too much toward certain universities, which has influenced the high school education policy so far. Also, it has caused a significant rise in tuition; with benefit principle, students cannot help being a burden by the high tuition. A bigger problem is that their diplomas cannot guarantee anything though they barely manage to get them. In summer 2011, finally, they burst into anger and despondency with a demonstration against the high tuition. The demonstration continues till now, which is to give out questions about the high tuition and the principle and direction of Korean education system. Is the university education privately owned or publicly owned? The government has announced various policies on college tuition cuts, but they have been invalid yet. Nevertheless, the demonstration threw a question about the publicness of education and showed the new starting point of higher education (Park, 1996).

\section{The New Ways for Positive Conflict}

What is clear is that harmony comes from conflict inevitably whether it is positive or not. Subsequently, what is the way of reducing negative conflicts but of causing positive conflicts? Good, says the Korean proverb, is from evil. As aforesaid, the Korean education system has been focused on elitism; paradoxically, it has raised the educational quality and has made students develop an eye for education. A positive change may occur by authentic education, and conversations and mutual trust based on in, not abandonment or extreme measures. Therefore, in this chapter, I would scrutinize the authentic education. In succession, I would suggest the social media-based bidirectional communication as a method to cause positive conflicts.

\subsection{The Authentic Education in Curriulum}

As shown in South Korean society, a positive conflict is started from the voluntary movements of individual students who are acutely aware of the problem. They are well aware of the problems relevant to the education system. They are well aware of the problems relevant to the education system. From where does this awareness come from? As Freire (2000) pointed out, the true meaning of awareness as a human being is acquired by only authentic knowledge and education.

Knowledge could be defined as something emerged by imposing mandates on the chaos that surrounds us. Knowledge is also something that fundamentally distinguishes human from the animals. However, it sometimes makes the world more inhumane and brute places (Parker, 1983). This statement may not imply that we do fail to apply knowledge on real lives. Rather, it imposes the ontological argument of knowledge; we might fail to know and develop the authentic knowledge from the chaos.

We might be seized by a delusion of that knowledge is neutral. However, we must not lose sight of that human being who has a certain recognition structure and a value system produce knowledge always. Therefore, knowledge may not be impartial from the worth; rather it contains values in itself and so dose do knowledge in the curriculum.

The knowledge in the curriculum should pursue a fount and passion of wisdom, and the harmonious relationship with the world around us; curriculum should provide knowledge that contains certain values and is connected to our lives. If students acquire knowledge based on the curriculum, this should guarantee that students have the proper hierarchy of values. To achieve this, knowledge in the curriculum should be intimately connected to students' real lives. Afterward, what is the education? Questions posed by Gandhi (1970) might provide some clues about the answer to the question.

A peasant earns his bread honestly. He has ordinary knowledge of the world. He knows fairly well how he should behave towards his parents, wife, his children and his fellow villagers. He understands and observes the rules of morality. But he cannot write his own name. What do you propose to do by giving him knowledge of letter? Will you add an inch to his happiness? Do you wish to make him discontented with his cottage or his lot? Now, let us take higher education. I have learned Geography, Astronomy, geometry, etc. What of that? In what ways have I benefited myself or those around me? Why have I learned these things? (Gandhi, 1970) 
Is the process of education in the curriculum a mere path for students to go to college and find a better job? In this case, some students who failed in entering college or finding a satisfactory job might be considered as that they did not learn anything from the curriculum. If not, there are still remained questions; what would students' lives be like after they learned according to the curriculum? What kinds of education should the curriculum provide to students?

We have been wanted to educating students by providing knowledge according to the curriculum. However, the authentic education that the curriculum provides should not be the intangible dream of that students' lives will be better when they have a lot of knowledge. Rather, there needs society's consensus on educational worth, for which the curriculum peruses.

As aforesaid, knowledge may not be neutral from the social values. On the supposition of that the core of the curriculum might be knowledge, the curriculum also should have an ability to combine knowledge, life and its worth. I may refer this combination as learning, which occurs inside of students.

The word "learning" is denoted 學習 in Chinese. 學習 indicates that there should be numerous practices (習) in order to understand something (學). As a little bird's wings are a raid blur of movement (白) as it flies (羽), learning requires students to live such a hectic study. True meaning of learning only arises when the knowledge is combined with students' lives with an intense introspection.

By supposing that the learning refers the rendezvous between knowledge and life, which occurs inside of students, education may indicate the engagement between students' own lives and lives that exist outside. In particular, education in the curriculum may occur only on the rendezvous of human-to-human: someone who teach and someone who learn. However, this does not mean subordinate relationship. There is a Chinese word "敎學相長" that represents the essential of this association, which means that teachers might be improved by teaching students; students may advance by learning from the teacher.

Although all sorts of delicacies were served, we cannot judge them unless we taste them. Likewise, although there are eternal verities of life, we cannot understand why it is so essential unless we learn it. Therefore, we only can aware what we did not know when we learn it. Also, we only can aware why it is hard to learn when we teach it. Therefore, teachers and students grow up together through the education (Confucius, 202 ).

Therefore, education in curriculum indicates the rendezvous of human-to-human that are equipotential to each other; they both can be teachers and students. We can start the authentic education with this point. The curriculum should provide knowledge that relates to social values based on the humans' equal relationship. Based on this relationship, students may recover their authority in symbiosis education system. In order to assure their equivalent, there needs to find ways to promise communication. Without a doubt, communication is the lifeline of all relationship. Meanwhile, there is a lack of ways for students to express their opinions, and this might lead a negative conflicts. However, the development of social media provides a space for communication beyond space and time.

\subsection{Positive Conflict and Social Media}

Communication makes convincing counterproposal and connects themselves with groups of like-minded persons. Mutual respect-based communication may be the key to the question, which has been made possible with Internet-based communication technology, namely social media.

There are various definitions as regards social media. Hobson (2011) defined social media as a product of advanced communication technologies and as media to ease communication. Vossen and Hagemann (2007) represented that users could socialize webs using them as their media. In the Kaplan (2010), social media are defined as open online tools and media platforms through which people share their thoughts, opinions, experiences and views. In addition, it mentioned that it is difficult to apply the production-consumption principle to social media that grow like an organism, wherein people share their information bidirectional and create contents by themselves.

Altogether social media are originated from the advancement of Internet media and are characterized by horizontal participation, networking and collective intelligence. In the past, the chance of expressing opinions was given only to some groups, whereas social media gives such chances to all people regardless of sex, age and background. So far the school policy has turned only on policy makers and interested parties, but now students have been able to make their voices. In the cyberspace of social media, moreover, they are given equal status with policy makers.

The social media network enables students to have a greater influence on the education system. Social media are not restricted by time and space, wherein they can meet many people and share their opinions in freedom. Writings posted on blogs can be read by other students and can be spread to like-minded ones after several days or months, where through realistic counterproposals are made by them. Thus, the network can be expanded unlimitedly. Thanks to 
social media, Choi was able to leave school and found an alternative school, and strange undergraduates are able to share their opinions on a network and hold a rally. They are the finest examples of the social media community. The information in social media is continuously upgraded by collective intelligence that is organically formed by many opinions, experiences and views. With participation and sharing, the majority opinion proposes various alternatives of which individuals have not thought.

On this wise, social media well shows the features of a positive conflict, i.e., mutual respect-based communication. As the case stands, the future education system is not confined to the development of effective educational programs and the one-sided impartation of knowledge but needs new paradigms such as the realization of bidirectional communication and the cultivation of social media commoners.

\section{Conclusions}

The word "curriculum" comes from the word "horserace." During a horserace, a jockey whips and spurs his horse with blinkers on so that it can outrun other horses. Do we want to the curriculum look like a horserace? The answer is no; it is problematic to apply a uniform system to students of different values and dreams, which may end in negative conflicts. Students are not supposed to be self-abandoned or dropouts. System Theory and Yin-Yang Theory tell that the education system, which does not allow students, will never produce satisfactory results inasmuch as positive conflicts to harmony are linked to the improvement of the education system.

In order to lead positive conflicts for harmony, what are ways to support students resolve their struggles in a positive direction? The first consideration is to listen to their voice and to recognize them as main agents of education. Second, various communication windows should be opened in order that they may lay bare their heart with an easy mind. Social media makes it possible to open windows through which individual stories can be told in real time, which suggests that students should be offered the best education and should be helped to develop an eye for education and moreover be given a chance to put forced their opinions.

The education system exists for the future of the society whereof leaders are contemporary students. Contemporary educators have a need to trust and back up our students so that they may autonomously create the harmony between Yin and Yang in the curriculum. For students to run for one's dream tapping creative and positive conflicts for harmony; that would be the true meaning of "horse race" of which the curriculum dreams.

\section{References}

Bevis, E. O., \& Watson, B. (1989). Toward a caring curricula: A new pedagogy for nursing. New York: National League for Nursing Press.

Confucius. (202). Book of rites (禮記). China.

Dewey, J. (1952). The child and the curriculum, and the school and society. Chicago: University of Chicago Press.

Freire, P. (2000). Pedagogy of the oppressed. New York: Contiuum.

Gandhi, M. (1970). My views on education. Bharatiya Vidya Bhavan.

Ha, Y. S. (2009). Multi-cultural education in South Korea. Research on social education, 48 (3), 117-132.

Hobson, J. (2011). Social media for researchers: Opportunities and challenges. MAI Review, 3, 1.

Kaplan, A. (2010). Users of the world, unite! The challenges and opportunities of social media. Business Horizons, 53(1), 59-68.

Kim, J, H., \& Lee, S. R. (2011). The investigation of the relationships among poverty, sociocultural background, environment and development of adolescent. Investigation of Adolescent, 18(5), 385-411.

Kim, K, G. (1996). The sociocultural backgrounds for the changes of population in South Korea: focusing on educational fever and economic progress. Journal of Educational Research, 6(1), 33-50.

Korea Educational Development Institute. (2011). Annual report and supply and demand on workers (ICN Publication No. 12-1204). Retrieved from http://www.incham. net

Lee, J. (1999). Historic factors affecting educational administration in Korean higher education. Higher Education Review, 32(1), 7-23.

Lee, J. K. (1997). Investigation on educational anthropology in South Korea. The Republic of Korea: How.

Lee, J. K. (1998). How can we save our children from educational fever. Journal of educational anthropology. 4 (2), 1-3.

Lee, M. H. (2011). A colonial education. Journal of Research on Independent of South Korea, 39, 77-126.

Lim, C. S. (1997). Vocational education in South Korea. Research on education and economics , 447-503.

Levin, B. (2008). Curriculum policy and the politics of what should be learned in schools. In F. M. Connelly (Ed.) with M. F. He and J. Phillion (Assoc. Eds), The sage handbook of curriculum and instruction (pp. 7-24). Thousand Oaks, CA: Sage.

McNeill, K. (2009). Teachers' use of curriculum to support students in writing scientific arguments to explain phenomena. Science Education, 93(2), 233-268.

National Youth Policy Institute. (2011). Social cultural context for education fever. In KEDI (Ed.), The future of South Korean Education 
(pp. 58-69) South Korea: KEDI.

Park, H. I. (1996). Historical background of educational fever in South Korea. The Republic of Korea: How.

Park, R. (1939). Symbiosis and socialization: A frame of reference for the study of society. American Journal of Sociology, $45(1), 1$.

Parker, P. (1983). To know as we are known: A spirituality of education. San Francisco: Harper \& Row.

Roderick, M. (2005). Retention under Chicago's high-stakes testing program: Helpful, harmful, or harmless? Educational Evaluation and Policy Analysis, 27(4), 309-340.

Sorokin, P. (1957). Social and cultural dynamics. New York: Bedminster Press.

Stainback, S., \&. Stainback, W. (1996). Inclusion : A guide for educators. Baltimore : P.H. Brookes Pub. Co.

von Bertalanffy, L. (1969). General system theory foundations, development, applications. New York: G. Braziller.

Vossen, G. \&. H., S. (2007). Unleashing web 2.0: From concepts to creativity. Ubiquity - Association for Computing Machinery, 2007(December) 1-3.

Westbury, I. (2008). Making curricula; why do states make curricula, and how? In F. M. Connelly (Ed.) with M. F. He and J. Phillion (Assoc. Eds), The sage handbook of curriculum and instruction (pp. 45-65). Thousand Oaks, CA: Sage.

Zhou Dun-Yi. (1175). Refractions on Things at Hands. China. 